\title{
Cytotoxic esterified diterpenoid alkaloid derivatives with increased selectivity against a drug-resistant cancer cell line
}

\author{
Koji Wada ${ }^{a, c}$, Emika Ohkoshia ${ }^{a}$, Susan L. Morris-Natschke ${ }^{a}$, Kenneth F. Bastow ${ }^{b}$, and Kuo- \\ Hsiung Lee ${ }^{a, d,{ }^{*}}$ \\ aNatural Products Research Laboratories, UNC Eshelman School of Pharmacy, University of \\ North Carolina, Chapel Hill, NC 27599-7568, USA \\ ${ }^{b}$ Division of Medicinal Chemistry, UNC Eshelman School of Pharmacy, University of North \\ Carolina, Chapel Hill, NC 27599-7568, USA \\ 'School of Pharmacy, Hokkaido Pharmaceutical University, 7-1, Katsuraoka-cho, Otaru \\ 047-0264, Japan \\ ${ }^{d}$ Chinese Medicine Research and Development Center, China Medical University and Hospital, \\ Taichung, Taiwan
}

\begin{abstract}
C-6 Esterifications of delpheline (1) were carried out to provide 20 new diterpenoid alkaloid derivatives (4-22, 24). Three natural alkaloids (1-3) and all synthesized compounds (4-25) were evaluated for cytotoxic activity against lung (A549), prostate (DU145), nasopharyngeal (KB), and vincristine-resistant nasopharyngeal (KB-VIN) cancer cell lines and interestingly, showed an improved drug resistance profile compared to paclitaxel. Particularly, 6-(4-fluoro-3methylbenzoyl)delpheline (22) displayed 2.6-fold greater potency against KB-VIN cells compared with the parental non-drug resistant KB cells. 6-Acylation of $\mathbf{1}$ appears to be critical for producing cytotoxic activity in this alkaloid class and a means to provide promising new leads for further development into antitumor agents.
\end{abstract}

\section{Keywords}

Delpheline; $\mathrm{C}_{19}$-diterpenoid alkaloid; Cytotoxicity

\begin{abstract}
Natural products have been the major sources of currently available anticancer drugs. According to a review of New Chemical Entities (NCE) from 1981 to 2006, approximately $73 \%$ of anticancer drugs were not purely synthetic compounds, with $47 \%$ being natural products, directly derived from natural products, or mimicking natural products in one form or another. ${ }^{1}$ Diterpenoid alkaloids have been isolated from the genera Aconitum, Consolida and Delphinium of the Ranunculaceae family, and the genus Spiraea of the Rosaceae family. Diterpenoid alkaloids are classified according to their chemical structure as $\mathrm{C}_{18}$-diterpenoid alkaloids, which have either a lappaconitine or a ranaconitine skeleton, $\mathrm{C}_{19}$-diterpenoid alkaloids, which have either an aconitine, lycoctonine, lactone-type, pyro-type, rearranged-
\end{abstract}

\footnotetext{
(C) 2011 Elsevier Ltd. All rights reserved.

"Corresponding author. Tel.: +1 919962 0065/0066; fax: +1 919966 3893. khlee@ unc.edu (K.-H. Lee).
}

Publisher's Disclaimer: This is a PDF file of an unedited manuscript that has been accepted for publication. As a service to our customers we are providing this early version of the manuscript. The manuscript will undergo copyediting, typesetting, and review of the resulting proof before it is published in its final citable form. Please note that during the production process errors may be discovered which could affect the content, and all legal disclaimers that apply to the journal pertain. 
type, or 7,17-seco-type skeleton, and $\mathrm{C}_{20}$-diterpenoid alkaloids, which have either an arcutine, atisine, denudatine, hetidine, hetisine, kusnezoline, napelline, racemulosine, tricalysiamide, or vakognavine skeleton. ${ }^{2-4}$ The pharmacological properties of aconitinetype $\mathrm{C}_{19}$-diterpenoid alkaloids, including aconitine, hypaconitine, jesaconitine, and mesaconitine, have been studied extensively and reviewed. 5,6 Two reports on the effects of $\mathrm{C}_{19}$-diterpenoid alkaloids on cancer cells have appeared in recent years. 8-O-Azeloyl-14benzoylaconine, an aconitine-type $\mathrm{C}_{19}$-diterpenoid alkaloid, exhibited antiproliferative activity, ${ }^{7}$ and the cytotoxic effects of various $\mathrm{C}_{19}$-diterpenoid alkaloids against tumor cell lines were reported. ${ }^{8}$ Our previous study demonstrated the effects of various naturally occurring and semi-synthetic $\mathrm{C}_{19}$ - and $\mathrm{C}_{20}$-diterpenoid alkaloids on growth of the A172 human malignant glioma cell line. ${ }^{9}$ Antitumor properties and radiation-sensitizing effects of various types of novel derivatives prepared from $\mathrm{C}_{19}$ - and $\mathrm{C}_{20}$-diterpenoid alkaloids were also investigated. ${ }^{10}$ Two novel hetisine-type $\mathrm{C}_{20}$-diterpenoid derivatives showed significant suppressive effects against the Raji non-Hodgkin's lymphoma cell line. ${ }^{11}$ In addition, the effects of various semi-synthetic novel hetisine-type $\mathrm{C}_{20}$-diterpenoid alkaloids on the growth of the A549 human lung cancer cell line were examined and subsequent structure-activity relationships for the anti-proliferative effects against A549 cells were considered. ${ }^{12}$ However, little information is available regarding the cytotoxic properties of lycoctoninetype $\mathrm{C}_{19}$-diterpenoid alkaloids and their chemically transformed products. Herein, we report our study results on the unique cytotoxic activities of delpheline (1), a lycoctonine-type $\mathrm{C}_{19^{-}}$ diterpenoid alkaloid, and its derivatives.

Delpheline (1), pacinine (2) and yunnadelphinine (3) were purified from the seeds of Delphinium elatum cv. Pacific Giant by a previously described procedure. ${ }^{13,14}$ Delpheline (1) was reacted with various acyl chlorides at $80^{\circ} \mathrm{C}$ in pyridine to give C-6 substituted benzoyl and cinnamoyl derivatives (4-22). Delpheline (1) and 6-(3-

trifluoromethylbenzoyl)delpheline (12) were hydrolyzed under acidic conditions to provide the 7,8-demethylene derivatives, 7,8-demethylenedelpheline $(\mathbf{2 3})^{15}$ and 7,8-demethylene-6(3-trifluoromethylbenzoyl)delpheline (24), respectively. Oxidation of delpheline (1) with $\mathrm{KMnO}_{4}$-acetone gave 19-oxodelpheline (25).

The three natural alkaloids (1-3) and all synthesized compounds (4-25) were evaluated for cytotoxic activity against four human tumor cell lines [lung carcinoma (A549), prostate carcinoma (DU145), nasopharyngeal (KB) and multi-drug resistant variant expressing Pglycoprotein (KB-VIN)]. Paclitaxel was used as a positive control (data shown in Table I).

Interestingly, the natural alkaloids (1-3) and synthetic analogs that did not contain a C-6 ester group $(\mathbf{2 3}, \mathbf{2 5})$ were inactive $\left(\mathrm{EC}_{50}>20 \mu \mathrm{M}\right)$. Thus, acylation of the C-6 hydroxy group of 1 was necessary for cytotoxic activity. The methylenedioxy group of a lycoctoninetype $\mathrm{C}_{19}$-diterpenoid alkaloid might also be necessary for an inhibitory effect against $\mathrm{A} 549$, DU145, KB and KB-VIN cell lines, as compound $\mathbf{2 4}$ lost activity against all cell lines compared with the related compound $\mathbf{1 2}$.

Among the C-6 esterified compounds, 4 [6-(4-chlorobenzoyl)delpheline], 20 [6-(4benzyloxybenzoyl)delpheline], and 21 [6-(3-fluoro-4-trifluoromethylbenzoyl)delpheline] exhibited the highest average potency over all cell lines (average $\mathrm{EC}_{50} 9.83,9.57$, and 9.41 $\mu \mathrm{M}$, respectively). However, compound 16 [6-(3-trifluoromethylcinnamoyl)delpheline] showed significantly increased cytotoxic activity $\left(\mathrm{EC}_{50} 10.2 \mu \mathrm{M}\right)$ against $\mathrm{A} 549$ cells compared with 4, 20, and 21, but was generally less potent against DU145, KB, and KBVIN cells. Compounds 7, 11, 14, and 17 were inactive against all four cancer cell lines, while 5, 6, 8-10, 13, and 18 showed very limited potency. 
The most striking observations from the data in Table 1 were the degree and relative ratio of $\mathrm{KB} / \mathrm{KB}-\mathrm{VIN}$ potency. Among the four cancer cell lines tested, the highest potency was found against the KB-VIN cell line by compounds $\mathbf{2 0 - 2 2}\left(\mathrm{EC}_{50} 4.22,4.40\right.$, and $4.71 \mu \mathrm{M}$, respectively), followed by compounds $\mathbf{1 9}, \mathbf{1 5}, \mathbf{4 , 1 6}$, and $\mathbf{1 2}\left(\mathrm{EC}_{50} 6.50,6.80,8.27,9.10\right.$, and $11.9 \mu \mathrm{M}$, respectively). Generally, all of the active compounds showed the highest potency against the KB-VIN cell line compared with the other three cancer cell lines tested. Moreover, compounds 4, 12, 20, and 21 displayed similar potency against the KB and KBVIN cell lines (ratio of $\mathrm{EC}_{50} \mathrm{~KB} / \mathrm{EC}_{50} \mathrm{~KB}-\mathrm{VIN}$ : 1.07, 1.25, 1.60, and 1.24, respectively). Even more notably, compounds 15, 19, 16, and 22 showed over twofold selectivity between the two cell lines, with highest cytotoxic activity against the KB-VIN cell line (ratio of $\mathrm{EC}_{50}$ $\mathrm{KB} / \mathrm{EC}_{50} \mathrm{~KB}-\mathrm{VIN}: 2.15,2.28,2.31$, and 2.57, respectively).

The identity of the substituent on the C-6 acyl group affected the cytotoxic potency. For instance, the compounds with the highest potency against the KB-VIN cell line contained chloro (4), fluoro $(\mathbf{1 5}, \mathbf{2 1}, \mathbf{2 2})$, trifluoromethyl $(\mathbf{1 2}, \mathbf{1 6}, \mathbf{2 1})$, ethoxy $(\mathbf{1 9})$, or benzyloxy $(\mathbf{2 0})$ substituents on the acyl group. Against the KB-VIN cell line, compounds $\mathbf{2 1}$ and $\mathbf{2 2}$ with both fluoro and trifluoromethyl/methyl groups were more potent than $\mathbf{1 2}$ with only a single trifluoromethyl group and even more potent than $\mathbf{5}$ with a single fluoro group. Similarly, compound 16 [6-(3-trifluoromethylcinnamoyl)delpheline] showed increased cytotoxic activity against most cell lines compared with the related fluorinated compounds 17 [6-(4fluorocinnamoyl)delpheline] and $\mathbf{1 8}$ [6-(6-trifluoromethylnicotinoyl)delpheline]. Moreover, compounds with nitro, methoxy, phenyl, trifluoromethoxy, trifluoromethythio, and methyl carboxylate groups on a C-6 benzoate ester were generally less potent.

In conclusion, we have synthesized various C-6 acylated derivatives of $\mathbf{1}$, a lycoctonine-type $\mathrm{C}_{19}$-diterpenoid alkaloid. All derivatives were screened against four tumor cell lines, and the C-6 acylated was found to be critical for cytotoxic activity. Compounds 4, 12, 20, and 21 displayed the greatest potency over all four tested cell lines. While these four compounds showed comparable potency against both KB and KB-VIN cancer cell lines, some compounds showed tumor-selective activity. Compounds 15, 16, 19, and 22 exhibited greater inhibitory activity against drug-resistant KB-VIN cells (2.15-2.57 fold) than the parental KB cells. Continued studies are merited to further develop these promising new leads as antitumor agents, particularly with enhanced tumor selectivity.

\section{Acknowledgments}

This study was supported by grant CA17625-32 from the National Cancer Institute awarded to K. H. Lee. This study was also supported in part by the Department of Health Cancer Research Center of Excellence (DOH-100TD-C-111-05).

\section{References and notes}

1. Newman DJ, Cragg GM. J. Nat. Prod. 2007; 70:461. [PubMed: 17309302]

2. Wang FP, Chen QH, Liu XY. Nat. Prod. Rep. 2010; 27:570.

3. Wang, FP.; Chen, QH. The Alkaloids. Cordell, GA., editor. Vol. Vol. 69. New York: Elsevier Science; 2010. p. 1-623.

4. Wang, FP.; Chen, QH.; Liang, XT. The Alkaloids. Cordell, GA., editor. Vol. Vol. 67. New York: Elsevier Science; 2007. p. 1-78.

5. Amiya, T.; Bando, H. The Alkaloids. Brossi, A., editor. Vol. Vol 34. San Diego: Academic Press; 1988. p. 95-179.

6. Joshi, BS.; Pelletier, SW. Alkaloids: Chemical and Biological Perspectives. Pelletier, SW., editor. Vol. Vol 13. Amesterdam: Pergamon; 1999. p. 289-370.

7. Chdoeva A, Bosc J-J, Guillon J, Decendit A, Petraud M, Absalon C, Vitry C, Jarry C, Robert J. Bioorg. Med. Chem. 2005; 13:6493. [PubMed: 16081293] 
8. de Ines C, Reina M, Gavin JA, Gonzalez-Coloma A. Z. Naturforsch. C. 2006; 61:11. [PubMed: 16610210]

9. Wada K, Hazawa M, Takahashi K, Mori T, Kawahara N, Kashiwakura I. J. Nat. Prod. 2007; 70:1854. [PubMed: 18044843]

10. Hazawa M, Wada K, Takahashi K, Mori T, Kawahara N, Kashiwakura I. Invest. New Drugs. 2009; 27:111. [PubMed: 18551247]

11. Hazawa M, Wada K, Takahashi K, Mori T, Kawahara N, Kashiwakura I. Invest. New Drugs. 2011; 29:1. [PubMed: 19784550]

12. Wada K, Hazawa M, Takahashi K, Mori T, Kawahara N, Kashiwakura I. J. Nat. Med. 2011; 65:43. [PubMed: 20706796]

13. Bando H, Wada K, Tanaka J, Kimura S, Hasegawa E, Amiya T. Heterocycles. 1989; 29:1293.

14. Wada K, Yamamoto T, Bando H, Kawahara N. Phytochemistry. 1992; 31:2135.

15. Narzullaev AS, Yunusov MS, Sabirov SS. Chemistry of Natural Compounds. 1989; 25:43.

Bioorg Med Chem Lett. Author manuscript; available in PMC 2013 January 1. 


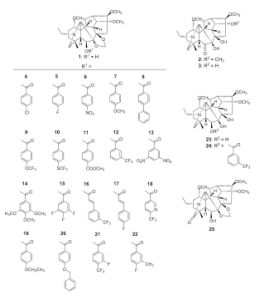

Figure 1. 


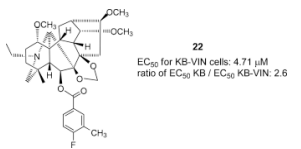

Figure 2. 
Table 1

Cytotoxic activity data for diterpenoid alkaloid and derivatives $\left[\operatorname{ED}_{50}(\mu \mathrm{M})\right]^{a, b}$

\begin{tabular}{ccccc}
\hline & A549 & DU145 & KB & KB-VIN \\
\hline $\mathbf{1}$ & $>20$ & $>20$ & $>20$ & $>20$ \\
$\mathbf{2}$ & $>20$ & $>20$ & $>20$ & $>20$ \\
$\mathbf{3}$ & $>20$ & $>20$ & $>20$ & $>20$ \\
$\mathbf{4}$ & $14.8 \pm 3.76$ & $7.40 \pm 1.16$ & $8.85 \pm 2.02$ & $8.27 \pm 1.62$ \\
$\mathbf{5}$ & $>20$ & $15.6 \pm 5.39$ & $>20$ & $15.0 \pm 6.51$ \\
$\mathbf{6}$ & $>20$ & $17.2 \pm 3.26$ & $>20$ & $17.7 \pm 3.51$ \\
$\mathbf{7}$ & $>20$ & $>20$ & $>20$ & $>20$ \\
$\mathbf{8}$ & $>20$ & $17.1 \pm 11.4$ & $>20$ & $17.4 \pm 7.42$ \\
$\mathbf{9}$ & $18.7 \pm 6.57$ & $20.3 \pm 7.06$ & $20.1 \pm 7.63$ & $18.9 \pm 4.95$ \\
$\mathbf{1 0}$ & $>20$ & $16.6 \pm 12.7$ & $>20$ & $17.9 \pm 4.16$ \\
$\mathbf{1 1}$ & $>20$ & $>20$ & $>20$ & $>20$ \\
$\mathbf{1 2}$ & $>20$ & $12.6 \pm 2.96$ & $14.9 \pm 4.93$ & $11.9 \pm 3.26$ \\
$\mathbf{1 3}$ & $>20$ & $>20$ & $19.1 \pm 4.78$ & $20.3 \pm 2.66$ \\
$\mathbf{1 4}$ & $>20$ & $>20$ & $>20$ & $>20$ \\
$\mathbf{1 5}$ & $19.9 \pm 10.1$ & $16.9 \pm 6.74$ & $14.6 \pm 7.05$ & $6.80 \pm 4.99$ \\
$\mathbf{1 6}$ & $10.2 \pm 2.62$ & $15.1 \pm 5.97$ & $>20$ & $9.10 \pm 1.51$ \\
$\mathbf{1 7}$ & $>20$ & $>20$ & $>20$ & $>20$ \\
$\mathbf{1 8}$ & $>20$ & $>20$ & $>20$ & $18.7 \pm 5.17$ \\
$\mathbf{1 9}$ & $20.0 \pm 0.89$ & $15.6 \pm 2.56$ & $14.8 \pm 3.27$ & $6.50 \pm 2.16$ \\
$\mathbf{2 0}$ & $14.1 \pm 2.93$ & $13.2 \pm 5.68$ & $6.76 \pm 1.74$ & $4.22 \pm 1.09$ \\
$\mathbf{2 1}$ & $16.5 \pm 2.24$ & $11.3 \pm 7.9$ & $5.44 \pm 1.75$ & $4.40 \pm 0.83$ \\
$\mathbf{2 2}$ & $>20$ & $19.8 \pm 4.58$ & $12.1 \pm 7.83$ & $4.71 \pm 1.44$ \\
$\mathbf{2 3}$ & $>20$ & $>20$ & $>20$ & $>20$ \\
$\mathbf{2 4}$ & $>20$ & $>20$ & $>20$ & $>20$ \\
$\mathbf{2 5}$ & $>20$ & $>20$ & $>20$ & $>20$ \\
Paclitaxel & $0.0064 \pm 0.0013$ & $0.0059 \pm 0.0019$ & $0.0060 \pm 0.0008$ & $0.76 \pm 0.22$ \\
\hline & & & &
\end{tabular}

${ }^{a}$ Cytotoxicity as EC50 values for each cell line, the concentration of compound that caused 50\% reducation in absorbance at $515 \mathrm{~nm}$ relative to untreated cells using sulforhodamine B assay.

${ }^{b}$ Lung carcinoma (A549), prostate carcinoma (DU145), nasopharyngeal (KB) and multi-drug resistant variant expressing P-glycoprotein (KBVIN). 